\section{A new NEDD8-ligating system for cullin-4A}

\author{
Fumio Osaka, ${ }^{1}$ Hiroshi Kawasaki, ${ }^{2}$ Noriko Aida, ${ }^{1}$ \\ Mihoro Saeki, ${ }^{1}$ Tomoki Chiba, ${ }^{3}$ \\ Seichi Kawashima, ${ }^{2}$ Keiji Tanaka, ${ }^{3}$ \\ and Seishi Kato ${ }^{1,4}$
}

\begin{abstract}
${ }^{1}$ Kato Cytoprotein N etwork Project, ERATO, Japan Science and Technology Corporation (JST), Sagami Chemical Research Center, Sagami hara, Kanagawa 229-0012, Japan; ${ }^{2}$ The Tokyo Metropolitan Institute of M edical Science, and ${ }^{3}$ CREST, Japan Science and Technology Corporation (JST), Bunkyo-ku,

Tokyo 113-0021, Japan

NEDD8 is a ubiquitin (Ub)-like protein. Here we report a novel ubiquitinylation-related pathway for modification by NEDD8. NEDD8 was activated by an E1 (Ub-activating enzyme)-like complex, consisting of APP-BP1 and hUba3 with high respective homologies to the aminoand carboxy-terminal regions of E1 and then linked to hUbc12 (a human homolog of yeast Ub-conjugating enzyme Ubc12p). The major target protein modified by NEDD8 was found to be Hs-cullin-4A (Cul-4A), a member of the family of human cullin/Cdc53 proteins functioning as an essential component of a multifunctional Ub-protein ligase E3 complex that has a critical role in Ub-mediated proteolysis.
\end{abstract}

Received A pril 10, 1998; revised version accepted May 27, 1998.

Ubiquitin (Ub), an 8.6-kD highly conserved protein, is covalently attached to target proteins by a multienzymatic system consisting of E1 (U b-activating), E2 (Ubconjugating), and E3 (Ub-ligating) enzymes to form the degradation signal for proteolytic attack by proteasomes (for review, see Hershko and Ciechanover 1992; Coux et al. 1996; Hochstrasser 1997; Varshavsky 1997). M oreover, various U b-like proteins are present universally in eukaryotes (for review, see Johnson and Hochstrasser 1997; Sai toh et al. 1997). Of them, SU M O-1 is capable of modifying RanGAP1 (Mahajan et al. 1997) or the PML protein (M üller et al. 1998). Intriguingly, its yeast homolog Smt3p was found to link covalently to target proteins by a new pathway rel ated to the U b system, activated by an Aoslp/U ba2p heterodimeric complex (Johnson et al. 1997) and conjugated by Ubc9p (Johnson and Blobel 1997; Schwarz et al. 1998) as the E1- and E2-like enzymes, respectively. The gene encoding NEDD8, another mammalian Ub-like protein, was identified as one of multiple neural precursor cell-expressed devel opmentally down-regulated genes in mice (Kumar et al. 1993;

[Key Words: U biquitin; ubiquitin-like protein; NEDD8; SUM O-1; cullin$4 \mathrm{~A} ; \mathrm{Cdc53}]$

${ }^{4}$ Corresponding author.

E-MAIL seishi@sagami.or.jp; FAX 81-427-49-7631.
Kamitani et al. 1997). NEDD 8 has the highest identity to Ub among many Ub-like proteins. The mechanism for ligation of NEDD8 to appropriate proteins, however, re mains largely unknown. In this study we report a novel modification system of NEDD8, consisting of the APP$\mathrm{BP} 1 / \mathrm{hU}$ ba3 heterodimer and hUbc12 as the E1- and E2like enzymes, respectively, which resembles that of the recently described Smt3p/SUM O-1, as mentioned above Johnson and Blobel 1997; Johnson et al. 1997; Schwarz et al. 1998), indicating that three distinct pathways for modification of $\mathrm{Ub}$ and $\mathrm{Ub}$-like proteins exist in cells. Moreover, we report that NEDD8 is likely to be conjugated to $\mathrm{Cul}-4 \mathrm{~A}$ via the carboxy-terminal Gly residue in a manner anal ogous to ubiquitinylation. Cul-4A is one member of a family of human cullin proteins (Kipreos et al. 1996). Yeast Cdc53p (a homolog of Hs-Cul-1) functions as a common subunit of the large $\mathrm{Ub}$ b-protein ligase E3 compl ex responsible for a ubiquitinylation-dependent proteolytic pathway that regulates various biologically important processes, such as the cell cycle, metabolism (M athias et al. 1996), and gene expression (for review, see Jackson 1996; Hershko 1997; Hoyt 1997). Therefore, the results obtained in this study suggest that modification of Cul-4A by NEDD 8 has an important role for regulation of the cell cycle.

\section{Results and Discussion}

Identification of a NEDD8-activating enzyme

To explore the conjugating mechanism of NEDD8, we first attempted to identify the protein(s) that can interact with human ${ }^{35} \mathrm{~S}$-labeled NEDD8 in rabbit reticulocyte lysates. Three major bands of 100, 66, and $30 \mathrm{kD}$ were reproducibly detected in addition to unmodified ${ }^{35} \mathrm{~S}$-labeled N EDD 8, and the 66- and 30-kD bands disappeared by treatment with the reducing reagent dithiothreitol (DTT) (Fig. 1A). To characterize these proteins, we isolated them from reticul ocyte lysates by affinity chromatography with GST-NEDD 8 fused protein as a ligand. Five proteins, 1-5 (see Fig. 1B), were eluted from the GST-NEDD8 column but not from the control GST resin. Proteins 1-3 were eluted by DTT (Fig. 1B, left); and proteins 4 and 5 by subsequent treatment with reduced glutathione, GSH (Fig. 1B, right).

Sequence analysis of the 62-kD protein 1 eluted from the GST-NEDD 8 affinity column showed that it was almost identical to the known protein, APP-BP1 (Fig. $2 \mathrm{~A}$ ), which had been found to interact with the APP, or $\beta$-amyloid precursor protein (Chow et al. 1996). APPBP1 showed strong similarity to the amino-terminal region of the Ub-activating enzyme E1; but this presumptive E1-like protein lacked the carboxy-terminal region containing the conserved Cys residue required for the formation of a thioester bond with Ub (Hatfield and Vierstra 1992; Dohmen et al. 1995), indicating that this protein perhaps differs from the DTT-sensitive 66-kD band shown in Figure 1A. In consi dering that the E1-like 


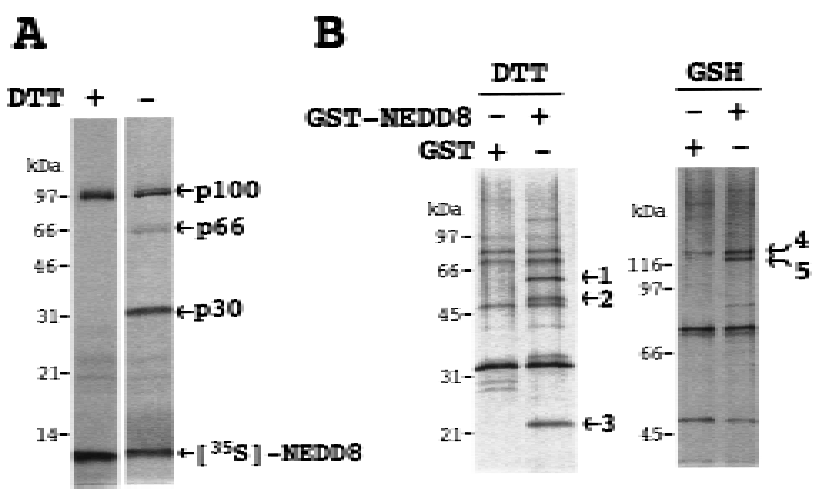

Figure 1. Analysis of proteins interacting with NEDD8 in rabbit reticulocyte lysates. (A) Analysis of proteins linked to ${ }^{35} \mathrm{~S}$ label ed N EDD8. After ${ }^{35}$ S-label ed N EDD 8 had been synthesized for $60 \mathrm{~min}$ at $30^{\circ} \mathrm{C}$ in $5 \mu$ of a reticulocyte lysate transcription/ translation system, samples $(2.5 \mu \mathrm{l})$ of the resultant translational products were subjected directly to SDS-PAGE in the presence $(+)$ or absence $(\rightarrow$ of DTT and autoradiographed. (B) SDS-PAGE analysis of proteins purified by GST -N EDD8-GSHSepharose 4B chromatography. After reticulocyte lysates had been applied to GSH-Sepharose 4B resin bearing GST or GSTNEDD8, the bound materials were eluted with $40 \mathrm{~mm}$ DTT (left) and subsequently with $30 \mathrm{~mm} \mathrm{GSH}$ (right). Samples were subjected to SDS-PAGE and stained with silver. Proteins bound specifically to GST-NEDD8 are numbered at right (1-5).

enzyme for Smt3p is a heterodimer of Aos1p and U ba2p, which correspond to the amino- and carboxy-terminal regions, respectively, homologous to E1 (Johnson et al. 1997), we predicted that a hypothetical protein with a similarity to the carboxy-terminal region of E1 that is capable of interacting with APP-BP1 must be present. We believed that U ba3p deposited in the yeast genome database (PIR accession no. S54087), with unknown function (Hochstrasser 1997), might be a possible candidate. By computer analysis in public databases we found a cDN A (GenBank accession no. AA 336365) encoding a human protein with a high homology to U ba3p and deduced its complete primary structure by CDNA sequencing (Fig. 2B). The hUba3 includes the consensus sequence for a nucleotide binding site, GXGXXG (position 55-60), which is present in Uba2p and E1 enzymes (Dohmen et al. 1995; Hass and Siepmann 1997) and also the consensus sequence PZCTXXXXP ( $Z$ is a nonpolar residue; position 214-222) around the essential Cys residue in E1 enzymes that becomes linked to $U b$ in an E1-Ub thioester linkage (Hatfield and Vierstra 1992; Dohmen et al. 1995). The protein, having $43 \%$ overall identity with yeast U ba3p, was thought to be a presumptive human homolog of the yeast Uba3p; therefore, we named it, tentatively, hU ba3. We assume that protein 2 of $\sim 50 \mathrm{kD}$ in Figure 1B may be hUba3, judging from its size and sensitivity to DTT; however, no sequence information is available.

To examine whether NEDD 8 is linked to hU ba3, ${ }^{35} \mathrm{~S}$ labeled hU ba3 was synthesized in an in vitro transcription-translation sytem in the presence of an excess amount of GST-NEDD8. A new band of $110 \mathrm{kD}$ was identified in addition to the unmodified ${ }^{35} \mathrm{~S}$-labeled hU ba3 (Fig. 2C), the intensity of which was increased by adding ${ }^{35}$ S-labeled APP-BP1. We concluded that this 110-kD band represented a complex formed by a thioester linkage between GST -N EDD 8 and ${ }^{35} \mathrm{~S}$-l abel ed hU ba3 because it was lost by treatment with DTT and no significant band was observed when the mutated GSTNEDD8, in which the carboxy-terminal Gly residue was deleted [termed N EDD $8(\Delta 76 \mathrm{G})$ ], was used instead of unmodified GST-NEDD8 (Fig. 2C). We also found that GST-SUM O-1 and GST-Ub did not link to ${ }^{35}$ S-labeled hUba3 and that GST-NEDD 8 did not form a linkage with ${ }^{35} \mathrm{~S}$-labeled APP-BP1 directly.

It was of interest to test whether APP-BP1 and hU ba3 form heterodimeric complex. To test this possibility, we carried out purification by $\mathrm{Ni}$-chelate column chromatography after ${ }^{35} \mathrm{~S}$-labeled (His) 6 -APP-BP1 had been incubated with ${ }^{35} \mathrm{~S}$-labeled hUba3 in reticulocyte lysates, and analyzed the eluates by SDS-PAGE and subsequent autoradi ography. Besides ${ }^{35} \mathrm{~S}$-labeled (His) 6 -APP-BP1, the band of ${ }^{35} \mathrm{~S}$-label ed hU ba3 was recovered, which was not evident when ${ }^{35} \mathrm{~S}$-labeled APP-BP1 was used instead of ${ }^{35} \mathrm{~S}$-labeled (His) ${ }_{6}$-APP-BP1 (Fig. 2D), suggesting strongly that both ${ }^{35} \mathrm{~S}$-labeled $(\mathrm{HiS})_{6}-\mathrm{APP}-\mathrm{BP} 1$ and ${ }^{35} \mathrm{~S}-$ labeled hUba3 were coeluted from the $\mathrm{Ni}$-chelate column by their complex formation. Therefore the APPBP1 and hUba3 form a complex, presumably a heterodimer, which is assumed to function as an E1-like enzyme for the activation of NEDD8.

\section{Identification of a NEDD8-conjugating enzyme}

We next carried out sequence analysis of the peptide fragments derived from the $22-k D$ protein 3 that interacted with GST-NEDD8 (see Fig. 1B) and found that three of the fragments obtained had high similarity to a cDNA clone deposited in GenBank (accession no. T48884). We sequenced the CDNA clone entirely and found that it encodes a protein that has $42 \%$ identity to Ubc12p, a member of the Ub-conjugating enzyme E2 family in yeast (SWISS-PROT accession no. P52491) (Fig. $3 A)$. Their sequence alignment showed that this newly identified protein is a human counterpart of yeast U bc12p. Therefore, we named it hUbc12 and predicted that $\mathrm{hUbc12}$ is a presumptive conjugating enzyme for NEDD8. Actually, the presumptive active Cys residue, required for the formation of a thioester bond between U b and a family of E2 enzymes (Jentsch 1992; Hass and Si epmann 1997), is conserved in hUbcl2 (see asterisk in Fig. 3A).

To validate this assumption, we examined whether ${ }^{35} \mathrm{~S}$-labeled hU bc12 forms a thioester linkage with GSTNEDD8 in reticulocyte lysates. When ${ }^{35}$ S-labeled hU bc12 was incubated with GST-N EDD8, a new larger band was evident besides ${ }^{35} \mathrm{~S}$-labeled hUbc12 but was not observed by treatment with DTT or when the mutated GST-NEDD8( $(46 \mathrm{G})$ mentioned above was used (Fig. 3B). Moreover, neither GST-Ub nor GST-SUM O-1 linked to hUbc12. These results indicate that hUbc12 
A

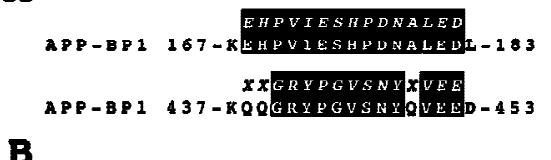

$\mathbf{B}$

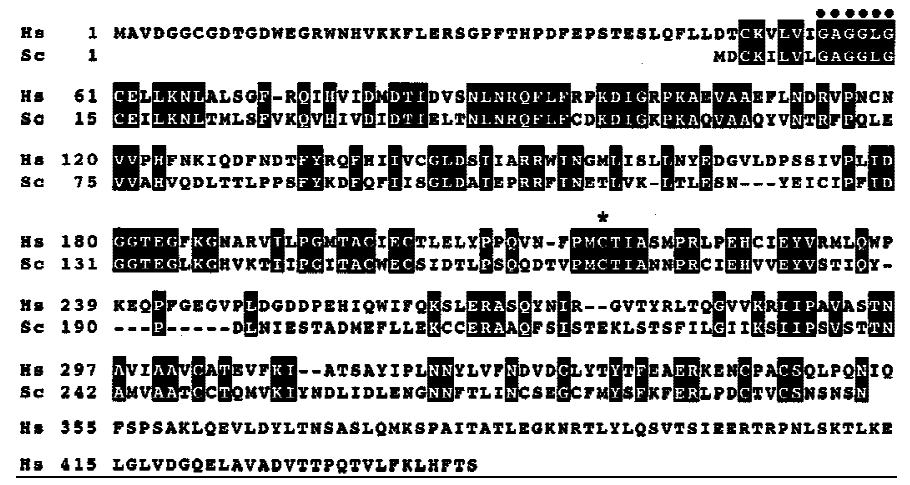

C

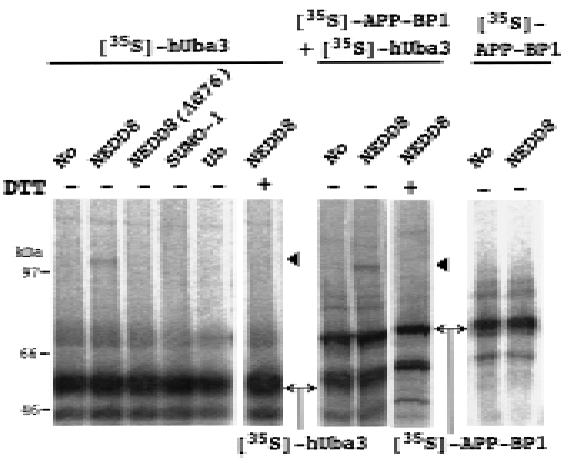

D

- - + + Wi-affinito

$-+-+\left[\mathrm{IS}_{\mathrm{SI}}\right]-\mathrm{BPF}-\mathrm{BPI}$

$-+-+-\left[35_{s]-1[i s)_{5}-\operatorname{agp}-\mathrm{ge} 1}\right.$

$+-++\left[^{35}\right.$ s] -hobas

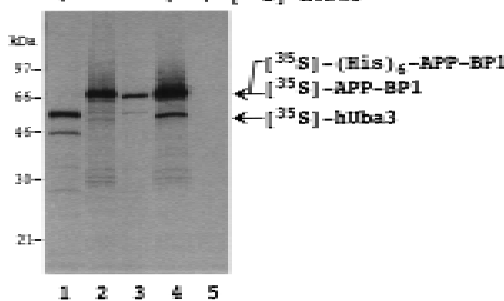

Figure 2. Identification of an E1-like APP-BP1/hU ba3 heterodimer for activation of N EDD8. (A) Sequence al ignment of two peptides of the rabbit 62-kD protein associated with GST-N EDD8 (band 1 in Fig. 1B) with human APP-BP1 (Chow et al. 1996). Partial amino acid sequences of the fragments of the 62-kD band digested with lysylendopeptidase were determined with a protein sequencer and are shown above the APP-BP1 sequences in italics. (X) An unidentified residue. The identical amino acids are boxed in black. (B) Primary structure of human U ba3 (Hs) deduced from the nucleotide sequence of a human cDNA and its sequence alignment with yeast Uba3p (Sc) (PIR accession no. S54087). Amino acid residues are numbered from the amino terminus. Identical amino acids are boxed in black. The motif shown $(\bullet)$ is the consensus sequence for a nucleotide binding site. The asterisk indicates the essential Cys residue conserved in El enzymes that becomes linked to Ub in an El-Ub thioester linkage. (C) Thioester linkage between ${ }^{35} \mathrm{~S}$-labeled hU ba3 and GST-NEDD $8 .{ }^{35} \mathrm{~S}$-Labeled hUba3 and/or ${ }^{35} \mathrm{~S}$-labeled APP-BP1 were cosynthesized for $60 \mathrm{~min}$ at $30^{\circ} \mathrm{C}$ in vitro in a $5 \mu \mathrm{l}$ reticulocyte lysate transcription/translation system in the presence of $0.35 \mu \mathrm{g}$ of unlabeled GST-N EDD8, GST-N EDD8( $\Delta 76 \mathrm{G}), \mathrm{GST}-S U$ M 0-1, or GST-Ub, and a part of each $(2.5 \mu \mathrm{l})$ was analyzed as in Fig. $1 \mathrm{~A}$. A rrowheads indicate the ${ }^{35} \mathrm{~S}-$ label ed hU ba3GST-NEDD 8 complex. (D) Complex formation between ${ }^{35} \mathrm{~S}$-labeled (His) ${ }_{6}-\mathrm{APP}-\mathrm{BP} 1$ and ${ }^{35}$ S-labeled hUba3. ${ }^{35}$ S-labeled APP-BP1, ${ }^{35}$ S-label ed $(\mathrm{His})_{6}-\mathrm{APP}-\mathrm{BP} 1$, and ${ }^{35} \mathrm{~S}$-label ed hU ba3 were synthesized individually for $60 \mathrm{~min}$ at $30^{\circ} \mathrm{C}$ in vitro, and $1 \mu \mathrm{l}$ of each was analyzed (lanes 1-3), as described in Fig. 1A. After samples (5 $\mu \mathrm{l})$ of ${ }^{35} \mathrm{~S}$-labeled (His) $)_{6}$-APP-BP1 or ${ }^{35} \mathrm{~S}$-label ed APP-BP1 had been incubated with ${ }^{35} \mathrm{~S}$-label ed hU ba3 $(5$ $\mu \mathrm{l}$ ) for $30 \mathrm{~min}$ at $30^{\circ} \mathrm{C}$, half of each sample was applied onto a $\mathrm{Ni}$-chelate column. After the column had been washed with $50 \mathrm{~mm} \mathrm{~N}$ a-phosphate buffer $(\mathrm{pH} 8.0)$ containing 0.5 $\mathrm{M} \mathrm{N} \mathrm{aCl}$, the materials eluted with $100 \mathrm{~mm}$ EDTA (lanes 4,5) were analyzed as in Fig. $1 \mathrm{~A}$.

presumably acts as an E2-like enzyme specific for the conjugation of NEDD8.

Covalent modification of Hs-cullin-4A by NEDD8

Finally, we attempted to clarify the nature of the 100-kD component linked to ${ }^{35} \mathrm{~S}$-labeled NEDD 8 that was resistant to treatment with DTT (see Fig. $1 \mathrm{~A}$, left lane). We detected two bands in the GSH eluate from the GSTN EDD 8 column (Fig. 1B, right, bands 4 and 5). We found that protein 5, but not 4, a protein of $\sim 120 \mathrm{kD}$, contained N EDD8 (perhaps GST -N EDD8) by immunoblotting with anti-N EDD8 antibody (data not shown) and therefore used it for chemical sequence analysis. Surprisingly it had a striking homology with Hs-cullin-4A (called simply Cul$4 A$ ), reported recently as a member of the cullin/Cdc53 family of proteins (Kipreos et al. 1996; Fig. 4A). We found the cDNA fragment of Cul-4A in our human cDN A bank (Kato et al. 1994) and called it Cul-4A(524C), because it covered the carboxy-terminal 524 amino acid residues, but lacked the short amino-terminal region. We next examined whether Cul-4A(524C) is modified by N EDD 8. ${ }^{35} \mathrm{~S}$-Labeled Cul4A (524C) was modified by GSTNEDD8 in reticulocyte lysates, which was insensitive to treatment with DTT (Fig. 4B). We al so found that the 20-kD fragment of Cul-4A covering the carboxy-terminal 171 amino acid residues, designated Cul-4A(171C), was sufficient for the formation of the linkage with GST-NEDD8 (Fig. 4C), indicating that NEDD8 is covalently linked to the carboxy-terminal region of Cul-4A. M oreover, no complex with ${ }^{35} \mathrm{~S}$-labeled Cul-4A was formed when the mutated GST-NEDD8( $\Delta 76 \mathrm{G})$, GST-SUMO-1, or GST-Ub was used instead of GST-NEDD8, implying that NEDD8 is conjugated to Cul-4A via the carboxy-terminal Gly residue in a manner anal ogous to ubiquitinylation (Hershko and Ciechanover 1992) and that the presently described novel ligation pathway for N EDD8 did not catalyze formation of a linkage between Cul-4A and Ub or SUMO-1. These findings indicate strongly that Cul-4A is a major target protein for modification by N EDD8. Recently, Kamitani et al. (1997) also found that an $\sim 90-k D$ NEDD8-modified protein, differing from RanGAP1, was detected in all mammalian cell lines tested. We presume that this protein is Cul-4A or is 

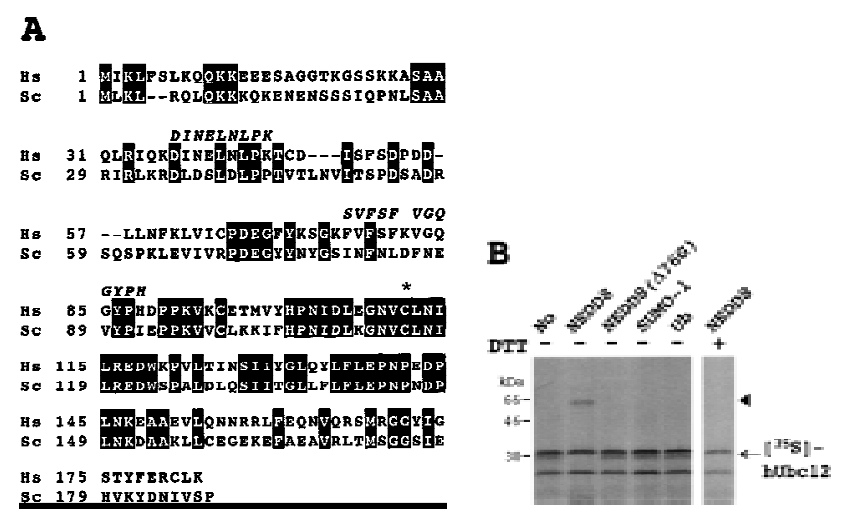

Figure 3. Identification of hUbc12 as a conjugating enzyme for NEDD8. (A) Primary structure of human Ubc12 (Hs) deduced from the nucleotide sequence of a human CDN A and sequence alignment with yeast Ubc12p (Sc) (SWISS-PROT accession no. P52491). The identical amino acids are boxed in black. The amino acid sequences of three peptides of the rabbit 22-kD protein associated with GST-N EDD8 (band 3 in Fig. 1B) are shown above the sequence of hUbc12. The asterisk indicates the essential Cys residue conserved in a family of U b-conjugating E2 enzymes that becomes linked to $\mathrm{U} b$ in an E2-Ub thioester linkage. (B) Thioester linkage between ${ }^{35} \mathrm{~S}$-labeled hUbc12 and GST-NEDD 8. ${ }^{35}$ S-Label ed hUbc12 synthesized in vitro in the presence of unlabeled GST-NEDD8, GST-NEDD8( $\Delta 76 \mathrm{G})$, GST-SUMO-1, or GST-Ub was analyzed as in Fig. 2. The arrowhead indicates the ${ }^{35} \mathrm{~S}$-labeled hUbc12-GST-NEDD8 complex.

in its family of proteins, although the nature of this 90 $\mathrm{kD}$ protein has not yet been characterized.

In the present study, we reported a novel modification system of NEDD8, consisting of the APP-BP1/hUba3 complex and hUbc12, which are related to E1 and E2 enzyme, respectively, in the ubiquitinylation pathway. This NEDD8-ligation pathway resembles that of Smt3p/SUM O-1, as mentioned in the introductory section (Johnson and Blobel 1997; Johnson et al. 1997; Schwarz et al. 1998). Intriguingly, quite recently Rublp, a presumptive yeast homolog of mammalian NEDD8 displaying 59\% amino acid identity to human NEDD8, was found to be ligated to target protein through Ulalp/ U ba3p and Ubc12p as the E1- and E2-like enzymes, respectively (Liakopoulos et al. 1998). In addition to the similarities in Uba3 and Ubc12 proteins between humans and yeast (Figs. 2B and 3A), APP-BP1 and Ulalp show high sequence similarity, that is, $26 \%$ amino acid identity, indicating evolutional conservation of the posttranslational protein-modifying system for Rublp/ NEDD 8 and a common role of this system in eukaryotes.

So far, it can be concluded that three different systems operate for activation of $\mathrm{Ub}$ and $\mathrm{U} \mathrm{b}$-like proteins: $\mathrm{A} U \mathrm{U}$ activating enzyme, E1, consisting of a singl e polypeptide, and two heterodimeric E1-like compl exes, A oslp/U ba2 $p$ and APP-BP1/hUba3 for activation of Smt3p/SUMO-1 and Rublp/NEDD8, respectively (this study; Johnson et al. 1997; Liakopoulos et al. 1998; for review, see Hochstrasser et al. 1998), al though there is no direct evidence that APP-BP1 and hUba3 form a heterodimer. It is notable that $\mathrm{Ub}$ is conjugated by multiple species of $\mathrm{Ubc}$, whereas Smt3p/SU M O-1 and N EDD 8 each use a specific conjugating enzyme, Ubc9 and hUbc12, respectively (this study; Johnson and Blobel 1997; Schwarz et al. 1998). Taken together, it is conceivable that three distinct pathways for modification of $U b$ and $U b$-like proteins exist in both yeast and mammalian cells.

Here, we reported that NEDD8 was likely to be conjugated to $\mathrm{Cul}-4 \mathrm{~A}$ via the carboxy-terminal Gly residue in a manner analogous to ubiquitinylation (Fig. 4B). Moreover, we observed that the carboxy terminal domain of Cul-4A, which has been conserved in various species (Kipreos et al. 1996), was sufficient for the conjugation of NEDD8 (Fig. 4C), indicating that the sites accepting NEDD8 exist in this region. One interesting aspect is that Cul-4A is one member of a family of human cullin proteins that have high sequence homologies (Kipreos et al. 1996). So far, 6 species of human cullin family proteins including Cul-1, Cul-2, Cul-3, Cul-4B, and Cul-5 in addition to Cul-4A have been reported
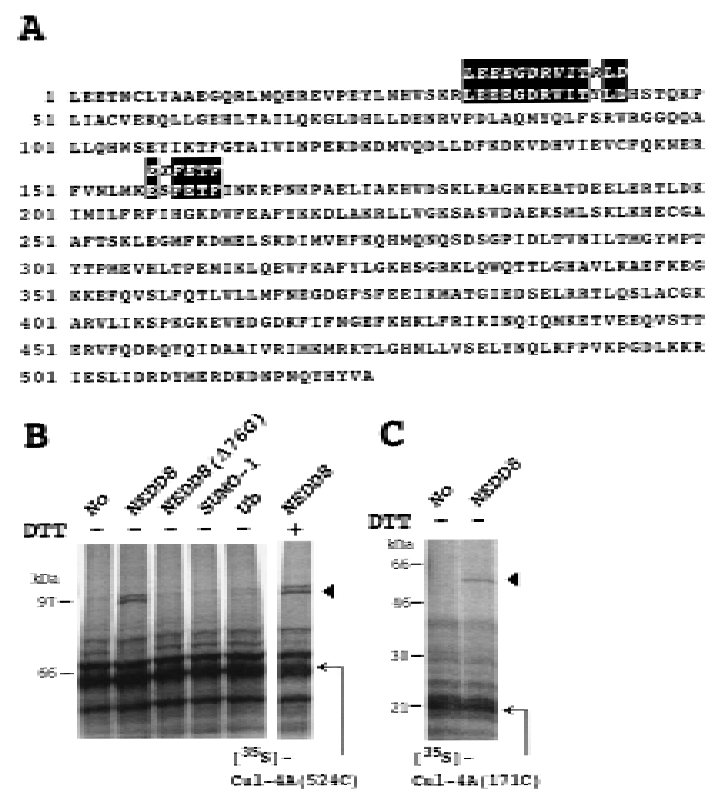

Figure 4. Linkage of NEDD8 to Cul-4A in a DTT-insensitive fashion. (A) Alignment of amino acid sequences of two peptides of the rabbit 120-kD protein associated with GST-N EDD8 (protein 5 band in Fig. 1B) and human Cul-4A that we had cloned. Identical amino acids are boxed in black. The Cul-4A CDNA was named Cul-4A (524C), as described in the text. (B) Linkage between ${ }^{35} \mathrm{~S}$-labeled Cul-4A(524C) and GST-N EDD 8. ${ }^{35} \mathrm{~S}$-labeled Cul-4A (524C) synthesized in vitro in the presence of unlabeled GST-N EDD8, GST-N EDD8( $476 \mathrm{G})$, GST-SUM O-1, or GST-Ub was analyzed as in Fig. $2 \mathrm{C}$. The arrowhead indicates the ${ }^{35}$ S-label ed Cul-4A (524C)-GST-N EDD 8 complex. (C) Linkage between ${ }^{35} \mathrm{~S}$-Labeled Cul-4A (171C) and GST-N EDD 8. ${ }^{35} \mathrm{~S}-$ label ed Cul-4A (171C) that corresponds to the carboxy-terminal 171 amino acid residues (see Materials and methods) was treated or not with unlabeled GST-NEDD 8 and analyzed as in $B$. The arrowhead indicates the ${ }^{35} \mathrm{~S}$-label ed Cul-4A (171C)-GSTNEDD8 complex. 
(Kipreos et al. 1996). Whether NEDD8 is also ligated to other cullin family proteins awaits further study.

The ligation of NEDD8 to Cul-4A was essentially the same as the recently observed conjugation of Rublp to yeast Cdc53p (homolog of Hs-Cul-1) (Lammer et al. 1998; Liakopoulos et al. 1998). Y east Cdc53p functions as a common component of a large $\mathrm{U}$ b-protein ligase E3 complex (called SCF Ub ligase) that regulates multiple cellular functions, such as $\mathrm{G}_{1}$ /S progression of the cell cycle (M athias et al. 1996; for review, see Jackson 1996; Hershko 1997: Hoyt 1997), gene expression ( $\mathrm{Li}$ and Johnston 1997), and methionine biosynthesis (Patton et al. 1998). Of them, it is of interest to consider a relationship between the NEDD 8 ligation system and the function of the SCF Ub ligase responsible for the ubiquitinylation of cell-cycle factors involved in the $\mathrm{G}_{1} / \mathrm{S}$ transition of the cell cycle (for review, see Jackson 1996; Hershko 1997; Hoyt 1997). Recently, Liakopoulos et al. (1998) reported that modification of yeast Cdc53p by Rublp may affect optimal assembly or function of the SCF complex, although RUB1, ULA1, UBA3, and U BC 12, all components of the NEDD 8 ligating system, are not essential for viability (Lammer et al. 1998; Liakopoulos et al. 1998). Moreover, a deletion of ENR2 (equivalent to ULA 1) is synthetic lethal with temperature-sensitive al leles of cdc34 (i.e., U BC3) and enhances the phenotypes of cdc4, cdc53, and skpl, all of which are components of the SCF Ub-ligase complex, implying that the Rublp ligation pathway is linked closely to cellcycle regulation (Lammer et al. 1998). Consistent with this notion, the mutation of hamster SMC, encoding a protein nearly identical to APP-BP1, is responsible for cell-cycle defects in the ts41 cell line (Handel and Weintraub 1992; Hochstrasser 1998). In considering these observations, the novel pathway for the ligation of NEDD8 to Cul-4A described here may provide new insight into understanding of the regulatory mechanism for ubiquitinylation mediated by the SCF Ub ligase.

\section{Materials and methods}

Biochemical analysis

Chemical analysis of proteins that interacted with the GST-NEDD8 fused protein was performed as follows: Fifty milliliters of rabbit reticulocyte lysate including $1 \mathrm{~mm}$ ATP, $1 \mathrm{~mm} \mathrm{M} \mathrm{gCl}, 0.5 \mathrm{~mm}$ DTT, $2 \mathrm{~mm}$ PMSF, $20 \mu \mathrm{g} / \mathrm{ml}$ aprotinin, and $20 \mu \mathrm{m}$ leupeptin was incubated for $15 \mathrm{~min}$ at $30^{\circ} \mathrm{C}$ with $5 \mathrm{mg}$ of GST-NEDD8 and then mixed at $4^{\circ} \mathrm{C}$ for $1 \mathrm{hr}$ with $2 \mathrm{ml}$ of GSH-Sepharose 4B (Pharmacia). The materials were then loaded onto a column and washed with $20 \mathrm{ml}$ of $50 \mathrm{~mm}$ Tris- $\mathrm{HCl}(\mathrm{pH}$ 8.0) containing $0.5 \mathrm{~m} \mathrm{NaCl}$. After washing, the absorbed materials were eluted with $20 \mathrm{~mm}$ Tris- $\mathrm{HCl}$ (pH 8.0), $40 \mathrm{~mm}$ DTT, and subsequently with $20 \mathrm{~mm}$ Tris- $\mathrm{HCl}(\mathrm{pH} 8.0), 30 \mathrm{~mm} \mathrm{GSH}$. The eluate was concentrated with a Microcon (Amicon). After SDS-PAGE, the protein fragments obtained by digestion with lysylendopeptidase were resolved by reversephase HPLC and sequenced by automated Edman degradation, as re ported previously (Kawasaki et al. 1990).

Molecular-biological analysis

The CDN As encoding human N EDD8 (accession no. D23662), SU M O-1, and $\mathrm{Cul}-4 \mathrm{~A}$ were found in our human full-length CDN A library prepared with a multifunctional shuttle vector, pKA1 (Kato et al. 1994). N ote that the Cul-4A CDNA lacked the short amino-terminal region and so was designated Cul-4A (524C), because it covered the carboxy-terminal 524 amino acid residues (see Fig. 4A). To make del etion mutants of the Cul$4 A$ CDNA, we digested the CDNA with EcoRI to remove the amino- terminal region, which left the carboxy-terminal 171 amino acid residues; thus, we termed the deleted CDNA Cul-4A(171C). The cDNA clones for $\mathrm{hU}$ ba3 and hU bc12 were obtained from ATCC and sequenced by a double-strand strategy in an automatic DNA sequencer. Various GST-fused proteins were synthesized in Escherichia coli using the pGEX-2TK expression vector (Pharmacia). The ${ }^{35} \mathrm{~S}$-methionine-labeled APP-BP1, ${ }^{35} \mathrm{~S}$-hU ba3, ${ }^{35} \mathrm{~S}$-labeled N EDD 8, ${ }^{35} \mathrm{~S}$-labeled (His) 6 -APP-BP1, ${ }^{35} \mathrm{~S}$-labeled Cul-4A (524C), and ${ }^{35} \mathrm{~S}$-labeled Cul-4A(171C) proteins were synthesized by an in vitro transcription/translation system according to the manufacturer's recommendations (Promega). CDNAs of APP-BP1 and GST-NEDD8( $\triangle 76 \mathrm{G})$ were prepared by PCR. The nucleotide sequence data reported in this paper will appear in the GSDB, DDBJ, EMBL, and $\mathrm{NCBI}$ nucleotide sequence databases under the following accession numbers: AB012190 for hU ba3, AB012191 for hU bc12, and AB012193 for Hs-Cullin-4A.

\section{Acknowledgments}

We thank Kazuo Kamemura, Akihiko Komuro, Toshiaki Suzuki, Nobuyuki Tanahashi, and our colleagues for advice throughout this study.

The publication costs of this article were defrayed in part by payment of page charges. This article must therefore be hereby marked "advertisement" in accordance with 18 USC section 1734 solely to indicate this fact.

\section{References}

Chow, N., J.R. Korenberg, X.-N. Chen, and R.L. N eve. 1996. APP-BP1, a novel protein that binds to the carboxyl-terminal region of the amyloid precursor protein. J. Biol. Chem. 271: 11339-11346.

Coux, O., K. Tanaka, and A.L. Goldberg. 1996. Structure and functions of the $20 \mathrm{~S}$ and $26 \mathrm{~S}$ proteasomes. Annu. Rev. Biochem. 65: 801-847.

Dohmen, R.J., R. Sappen, J.P. McGrath, H. Forrova, J. Kolarov, A. G offeau, and A. Varshavsky. 1995. An essential yeast gene encoding a homolog of ubiquitin-activating enzyme. J. Biol. Chem. 270: 1809918109.

Handeli, S. and H. Weintraub. 1992. The ts41 mutation in Chinese hamster cells leads to successive $S$ phases in the absence of intervening G2, M, and G1. Cell 71: 599-611.

Hass, A.L. and T.J. Siepmann. 1997. Pathways of ubiquitin conjugation. FASEB J. 11: 1257-1268.

Hatfield, P.M . and R.D. Vierstra. 1992. Multiple forms of ubiquitin-activating enzyme E1 from wheat. J. Biol. Chem. 267: 14799-14803.

Hershko, A. 1997. Roles of ubiquitin-dependent proteolysis in cell cycle control. Curr. O pin. Cell. Biol. 9: 788-799.

Hershko, A. and A. Ciechanover. 1992. The ubiquitin system for protein degradation. Annu. Rev. Biochem. 61: 761-807.

Hochstrasser, M. 1997. U biquitin-dependent protein degradation. Annu. Rev. Genet. 30: 405-439.

Hochstrasser, M. 1998. There's the Rub: A novel ubiquitin-like modification linked to cell cycle regulation. Genes \& Dev. 12: 901-907.

Hoyt, M.A. 1997. Eliminating obstacles: Regulated proteolysis in the eukaryotic cell cycle. Cell 91: 149-151.

Jackson, P.K. 1996. Cell cycle: Cull and destroy. Curr. Biol . 6: 1209-1212.

Jentsch, S. 1992. The ubiquitin-conjugation system. Annu. Rev. Genet. 26: 179-207.

Johnson, E.S. and G. Blobel. 1997. U bc9p is the conjugating enzyme for the ubiquitin-like protein Smt3p. J. Biol. Chem. 272: 26799-26802.

Johnson, E.S., I. Schwienhorst, R.J. Dohmen, and G. Blobel. 1997. The ubiquitin-like protein Smt3p is activated for conjugation to other proteins by an Aoslp/U ba2p heterodimer. EMBO J. 16: 5509-5519.

Johnson, P.R. and M. Hochstrasser. 1997. SUMO-1: Ubiquitin gains weight. Trends Cell Biol. 7: 408-413.

Kamitani, T., K. Kito, H.P. N guyen, and E.T. Y eh. 1997. Characterization of NEDD8, a developmentally down-regulated ubiquitin-like protein. J. Biol. Chem. 272: 28557-28562.

Kato, S., S. Sekine, S-W. Oh, N-S. Kim, Y. Umezawa, N. Abe, M. Yokoyama-Kobayashi, and T. Aoki. 1994. Construction of a human fulllength cDNA bank. Gene 150: 243-250.

Kawasaki, H., Y. Emori, and K. Suzuki. 1990. Production and separation of peptides from proteins stained with Coomassie Brilliant Blue R250 after separation by sodium dodecyl sulphate-polyacrylamide gel 


\section{Osaka et al.}

electrophoresis. Anal. Biochem. 191: 332-336.

Kipreos, E.T., L.E. Lander, J.P. Wing, W.W. He, and E.M. Hedgecock. 1996. cul- 1 is required for cell cycle exit in C. el egans and identifies a novel gene family. Cell 85: 829-839.

Kumar, S., Y. Yoshida, and M. Noda. 1993. Cloning of a CDNA which encodes a novel ubiquitin-like protein. Biochem. Biophys. Res. Commun. 195: 393-399.

Lammer, D., N. Mathias, J.M. Laplaza, W. Jiang, Y. Liu, J. Callis, M. Goebl, and M. Estelle. 1998. Modification of yeast Cdc53p by the ubiquitin-related protein Rublp affects function of the $\mathrm{SCF}^{\mathrm{Cdc4}} \mathrm{com}$ plex. Genes \& Dev. 12: 914-926.

Li, F.N. and M. Johnston. 1997. Grrl of Saccharomyces cerevisiae is connected to the ubiquitin proteolysis machinery through Skpl: Coupling glucose sensing to gene expression and the cell cycle. EMBO J. 16: 5629-5638.

Liakopoul os, D., G. Doenges, K. Matuschewski, and S. Jentsch. 1998. A novel protein modification pathway related to the ubiquitin system. EMBO J. 17: 2208-2214.

Mahajan, R., C. Del phin, T. Guan, L. Gerace, and F. Melchior. 1997. A small ubiquitin-related polypeptide involved in targeting RanGAP1 to nuclear pore complex protein RanBP2. Cell 88: 97-107.

M athias, N ., S.L. Johnson, M. Winey, A.M. Adams, L. Goetsch, J.R. Pringle, B. Byers, and M.G. Goebl. 1996. Ced53p acts in concert with $\mathrm{Cdc} 4 \mathrm{p}$ and $\mathrm{Cdc} 34 \mathrm{p}$ to control the $\mathrm{G}_{1}$-to-S-phase transition and identifies a conserved family of proteins. Mol. Cell Biol. 16: 6634-6643.

Müller, S., M.J. Matunis, and A. Dejean. 1998. Conjugation with the ubiquitin-rel ated modifier SU M O-1 regulates the partitioning of PM L within the nucleus. EMBO J. 17: 61-70.

Patton, E.E., A.R. Willems, D. Sa, L. Kuras, D. Thomas, K.L. Craig, and M. Tyers. 1998. Cdc53 is a scaffold protein for multiple Cdc34/Skp1/ F-box protein complexes that regulate cell division and methionine biosynthesis in yeast. Genes \& Dev. 12: 692-705.

Saitoh, H., R.T. Pu, and M. Dasso. 1997. SUM O-1: Wrestling with a new ubiquitin-related modifier. Trends Biochem. Sci. 22: 374-376.

Schwarz, S.E., K. Matuschewski, D. Liakopoulos, M. Scheffner, and S. Jentsch. 1998. The ubiquitin-like proteins SMT3 and SU M O-1 are conjugated by the UBC9 E2 enzyme. Proc. Natl. Acad. Sci. 95: 560-564.

Varshavsky, A. 1997. The ubiquitin system. Trends Biochem. Sci 22: 383-387. 


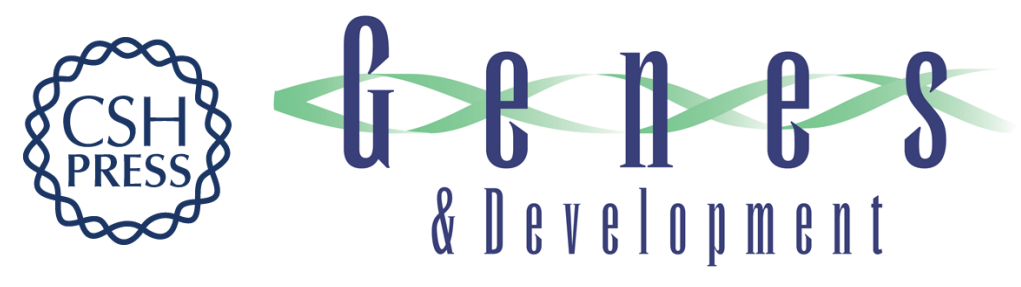

\section{A new NEDD8-ligating system for cullin-4A}

Fumio Osaka, Hiroshi Kawasaki, Noriko Aida, et al.

Genes Dev. 1998, 12:

Access the most recent version at doi:10.1101/gad.12.15.2263

References This article cites 31 articles, 14 of which can be accessed free at: http://genesdev.cshlp.org/content/12/15/2263.full.html\#ref-list-1

License

Email Alerting Receive free email alerts when new articles cite this article - sign up in the box at the top Service right corner of the article or click here.

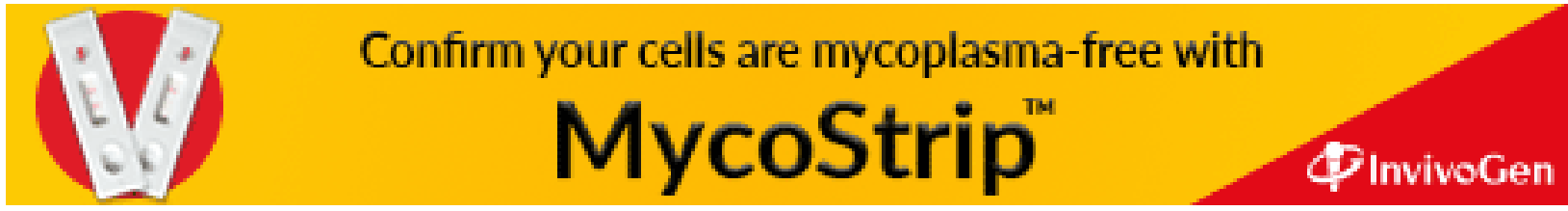

